\title{
To Be a "Bridge Over Troubled Water"*
}

\author{
Geon Ho Bahn \\ Editor-in-Chief, Korean Academy of Child and Adolescent Psychiatry
}

This journal has a new menu, "Online first." In order to do this, we need to hasten the review process of the manuscripts, cooperate closely with the publishing company, and collaborate with INFOrang to obtain technical support. While the printed journal will be published on July 1, two articles were published as an "Epub ahead of print" on June 1 , and five articles on June 12. I hope these articles, published earlier than scheduled, can be delivered, read, downloaded, and cited by the specialists of mental health for children and adolescents.

Thanks to "Online first," I was able to preview the final versions of the manuscripts published in this issue and was able to write editorials at my own pace. As I read these topics, I recognized that they not only focus on disorders such as attention-deficit/hyperactivity disorder (ADHD) and autism spectrum disorder but also on the sociocultural phenomena such as disasters, out-of-school adolescents, suicide in adolescents, and Internet addictions. Soo-Young Bhang reviewed the assessment tools for the mental health of school-aged children and adolescents exposed to disasters from 1988 to 2015. This review article will be a must-read for professionals working in this field. Out-of-school youths are one of the problems in our society today. So Hee Lee has been studying the psychological trauma in youth who left school or are expelled from school. Yong-Sil Kweon explored the risk factors of adolescent suicidal thoughts and attempts. Masaru Tateno submitted a paper on the relevance of Internet addiction and ADHD in Japanese college students. ADHD remains a major concern in the field of pediatric psychiatry. Bongseog Kim evaluated the efficiency of the ADHD-after school checklist, and Subin Park examined the ADHD-stigma questionnaire. Jung-Woo Son's "Autism and Beauty" is an interesting paper, verified by a brain imaging study, on the aesthetic judgment task response of patients with autistic spectrum disorder.

When I was about to finish editorials, I heard the breaking news. The World Health Organization announced that 'gender incongruence' is not classified as one of mental health but as one of sexual health and that 'gaming disorder' is newly introduced as one of mental health part of the codes in ICD-11. The Korean Academy of Child and Adolescent Psychiatry (KACAP) consists of a group of psychiatrists specializing in children and adolescents, and the official journal of KACAP (JKACAP) has dealt with pediatric psychiatric disorders. Child and adolescent psychiatrists now face changes of a definition of mental disorder which reflect both cultural and social issues. So far, doctors have been busy treating illnesses within the walls of a hospital. From now on, doctors would help children who are in a small boat drifting in a rough storm, adolescents isolated in a desert island, and youth who are frustrated and lost hope. JKACAP should serve as a "bridge over troubled water."

"Sail on silver girl

Sail on by

Your time has come to shine

All your dreams are on their way

See how they shine

Oh, if you need a friend

I'm sailing right behind

Like a bridge over troubled water

I will ease your mind

Like a bridge over troubled water

I will ease your mind"*

* Lyrics by Paul Simon (1970). 